\title{
Graphic Representation of Landslides Board Game for Ecological Education
}

\author{
Syuan-Lan, Shih, Fang-Lin Chao, and Wen-Ting Tao
}

\begin{abstract}
The purpose of graphic representation design of landslides board game is enhancing visual communication of ecological concept. The game enables people to experience different situations. The high attraction allows people to play continuously with graphic representation. The game keeps users informed about what is going on through appropriate graphic representation with self-explained abilities. The study based on the Eco-run board game - 3D structure to emulate the geographic landscape. Through the contents of the event card, we prompted the importance of communication between artist and scientist. The evaluations confirmed the graphic representation made participant aware its relationship more natural.
\end{abstract}

Index Terms-Board game, ecological education, graphic design, landslides.

\section{INTRODUCTION}

\section{A. Natural Disaster}

Climate change and over-exploitation caused the natural disaster, as we are concerned about the issue. Many rainfall-induced severe, large-scale landslides and debris flow occurred during the last two decades in Taiwan [1]. Massive landslides block rivers and form landslide dams the ecological importance of wood debris to forested stream ecosystems [2]. Biomaterials were installed on slopes, channel bed and along river banks [3]. Bioengineering techniques using vegetative check dams were found to be a practical solution for flood hazard minimization [4]. The Legislative Yuan passed the Environmental Education Act in 2011. Attractive education facilities have a demand in the future. This study aimed to improve the graphic representation of $3 \mathrm{D}$ board game which transfer eco-conscious more easily and encourage primary school students playing and acquire the environmental experiences.

\section{B. Environmental Education}

The gap between the possession of ecological knowledge and awareness, and displaying pro-environmental behavior has studied. Factors included demographic factors, external factors. Experiences have a stronger inference of people's behavior. Indirect experiences of passive learning lead to a weaker correlation between attitude and behavior. The related issues included [4]:

- The person is familiar with the environmental problem and its causes.

- The person knows how to act to lower impact on the

Manuscript received June 14, 2018; revised August 13, 2018.

The authors are with the Chaoyang University of Technology, Taiwan (e-mail: flinchao@gmail.com). environmental issue.

- Locus of control: Individual's perception of whether he or she can bring about change.

- Attitudes: People with pro-environmental attitudes are more likely to engage in those behaviors.

The game enables people to experience different situations. Teachers with positive environmental attitudes, high levels of ecological sensitivity, and a moderate level of internal locus of control [4] lead to motivation to the environment.

\section{BOARD GAME}

\section{A. Coverage}

The educational game also rewards the user with learning. The sensation that gamers term 'fun' derived from the act of mastering new knowledge, skills or experience. Traditionally, board games played with two or more people. The user faces problems and challenges then generate a strategy to win a game [5]. Significant aspects of play are (a) story which includes all plot and character development; (b) mechanics involve the procedure that provides the structure by which user interacts with, and (c)interface which addresses the usability in system elements [6]. A game mechanism is a "rule of interaction that implements an action in the game." If the controls are not intuitive enough [7], the user will always be distracted by it.

\section{B. User Interface}

If the environmental content built in the game, it is possible to extend learning span. Users have to concentrate on current situations and feel that he can practice strategy requires reaching the target. The user interface goal is to allow efficient operation of the apparatus, while the game feeds back information. It included plate, game cards, tools, and the rules that precede the game. Users should not wonder whether different words, situations mean the same thing. The game can keep users informed about what is going on through feedback. The user recognizes items more natural. Consequently, the graphic representation design should fulfill those requirements.

\section{The ELEMENT OF Associated KNOWLEDGE}

Based on the Eco-run [8] (Fig. 1), land conservation board game, where the main table field is a curvature $3 \mathrm{D}$ structure to emulate the geographic landscape. Three-dimension component allows users to follow the impact of a landslide. With the events in mind, the board game concentrate on related activities and corresponding elements include slopes 
board, air guns, earth and stone, trees, betel nut trees, dice, event cards, flags. Table platform of the three-dimensional landscape indicates a structure with a high and low gradient. There are typhoons and earth landslide and other disasters, so we design dolls by revealing their image. Air guns which emulate the severe wind in Typhoon, rock in different size which mimics the rock impact effect. The cards (Fig. 2) contain both positive and negative events which guiding the corresponding action within the game. The ecological environment theme-related cards activate the response of the situations. The 21 cards include in Table I.

TABLE I: CARDS NUMBERING AND MEANING

\begin{tabular}{lll}
\hline A: forest & B: water & C: land \\
\hline A1 seeding cultivation & $\begin{array}{l}\text { B1 flood control } \\
\text { report back }\end{array}$ & C1 planting bamboo \\
A2 rental reforestation & $\begin{array}{l}\text { C2 ecological } \\
\text { construction }\end{array}$ \\
$\begin{array}{l}\text { A3 banning stolen } \\
\text { forest thief }\end{array}$ & $\begin{array}{l}\text { B2 wetland } \\
\text { rehabilitation }\end{array}$ & $\begin{array}{l}\text { C3 following } \\
\text { conservation law }\end{array}$ \\
$\begin{array}{l}\text { A4 overusing } \\
\text { chemical }\end{array}$ & $\begin{array}{l}\text { B3 water reserve in } \\
\text { land }\end{array}$ & $\begin{array}{l}\text { C4 overexploiting for } \\
\text { villa }\end{array}$ \\
A5 deforestation & B4 valley flash flood & C5 slipping and road \\
A6 deforestation for & B5 debris flow & collapsing \\
betel tree & B6 embankment & C6 building road local \\
A7 excessive & undermining & spoil \\
deforestation & B7 reservoir siltation & C7 overbuilding golf \\
& & course \\
\hline
\end{tabular}

All contents of the cards relate to environmental issues (golf courses, tourist areas, farmhouses, excessive planting of fruit trees/ tea trees, mountain roads extension, destruction of forests, mountain road collapse, stratigraphic sliding). Through the contents of the event card, we bring the player into a soil and water conservation situation.

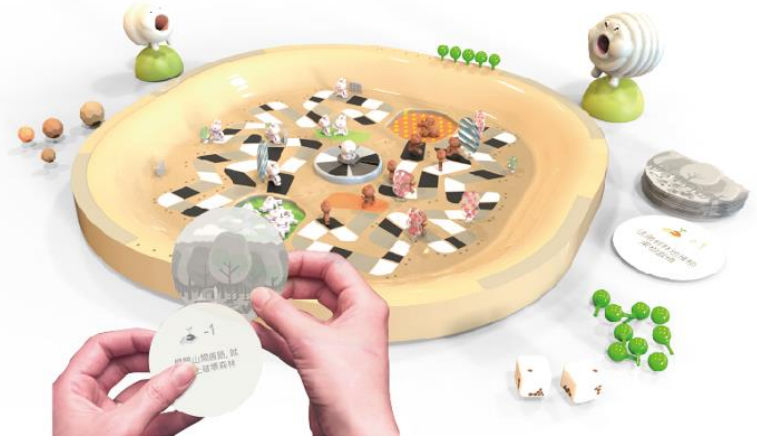

Fig. 1. The Eco-run, land conservation board game, where the main table field is a curvature 3D structure to emulate the geographic landscape. 3-D component allows users to follow the impact of a landslide.

As shown in Fig. 2, the information structure of water, forest, and land are suitable for learning. By interview with users, we extracted essential phrases in the sentence collected from student's comments and found the "graphic representation need improve" also shown the consistency between text and graphic led some confusions. It suggested graphic representation to adapt to users' prior experience.

\section{THE REDESIGN OF GRAPHIC REPRESENTATION}

Base on the interface design rules mention above; we modify the design to be more visible, matching with user experience, and reduce memory load by improving the speed of recognition. Terminology means specific words of ecology or sociology environment. Younger children have difficulty in understanding the content of cards and its relationship, so card needs re-organizing. In the previous study [8], we re-organized of cards by KJ method. By grouping the cards, we found three sub-groups. In each sub-group, we characterized as a positive and negative effect. Try to balance with positive and negative impact in sub-group and reconnect the cards group with user strategy. Due to space limitation, twelve of graphic representation and the ecology content of the cards will discuss and review here (Fig. 3).

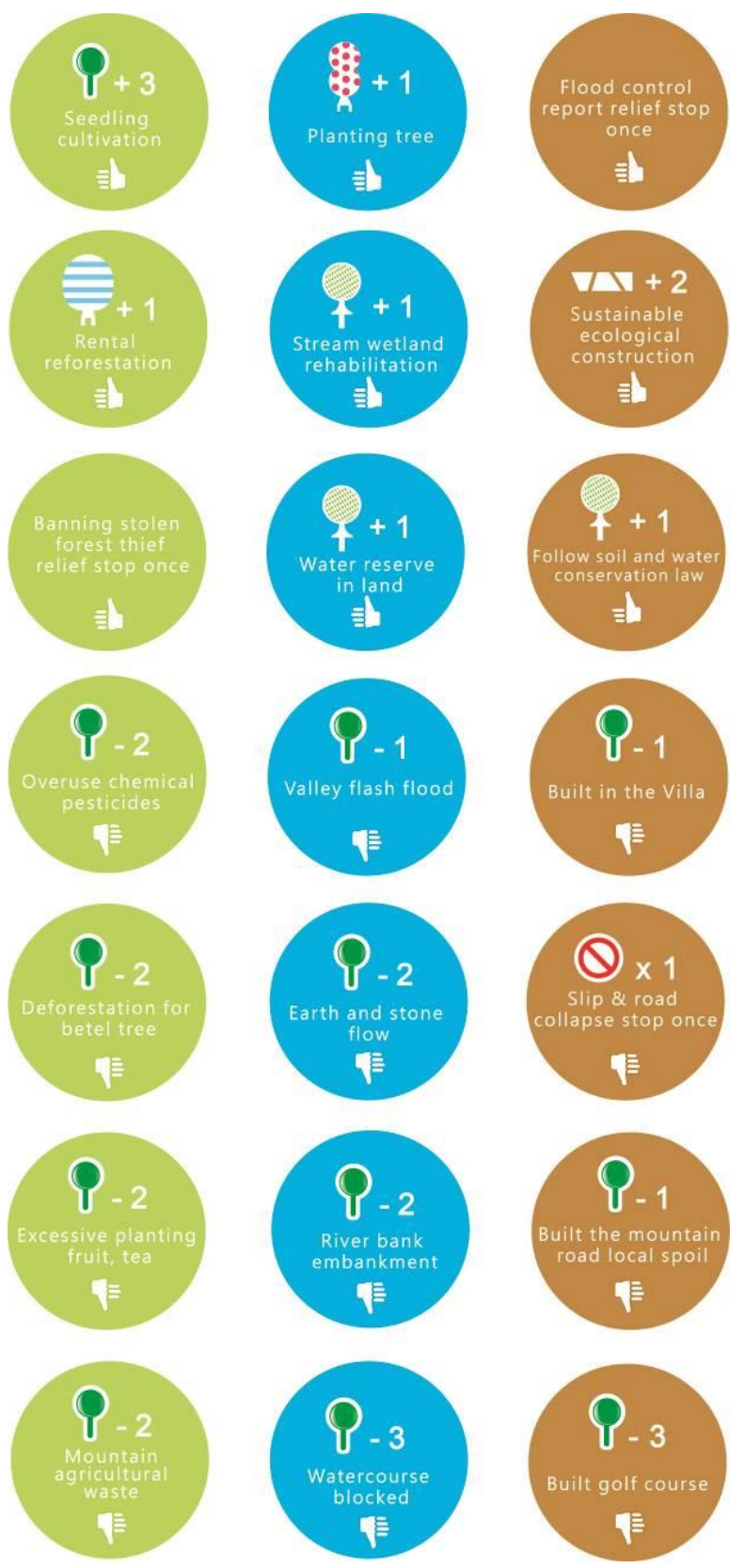

Fig. 2. The design of 21 eco-event cards.

\section{Evaluations}

The evaluation of the pattern design divided into two parts. First, we invite the average user (student) to watch and try to understand the meaning of the picture, and then give a rating 
on their intuition. In this part, we can understand the general public acceptance of the design of the pattern. Secondly, we invite experts to advise on professional aspects concerning the closeness of knowledge of earth and stone flow. Because earth-rock flow and ecological conservation are a specialized discipline, can these patterns be able to convey the meaning of the text content? Professional evaluation is necessary. The general user and the expert's perspective are different. Both of these opinions can provide designers and become the basis for improvement. The future designer will be able to convey the specific content of science education after correcting the design of the pattern. Let users more directly understand the issues.

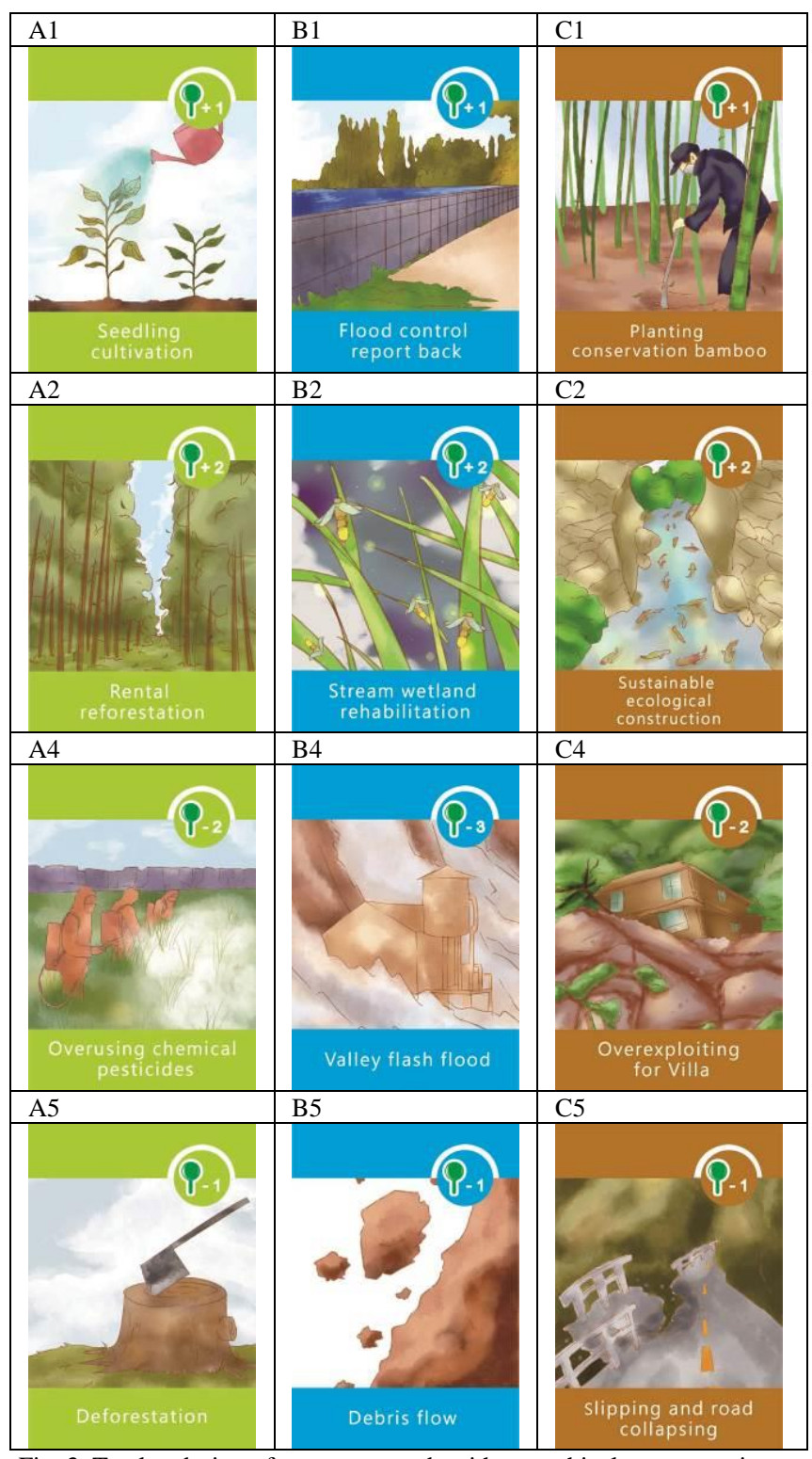

Fig. 3. Twelve design of eco-event cards with a graphical representation.

\section{A. Evaluation I}

Students of the year-1 group in our university I (age 18-20) are invited to play to gather user responses. Our design aims at the beginning level of the environmental education contents. While initial design draw, students are encouraged to play to gather user response. Evaluator requested user to re-associate with text content with the score range from 0-5.

After the player filled out the questionnaire, the evaluator also recorded a log of the player's actions, failures, and coded each of these reasons. Most of them have positive feedback. The average identification score of the group (average years of old in the group is 18.3) is 4.14. There is some figure earned a lower rating (below 3.8), namely A2, B1, B2, B4, and $\mathrm{C} 2$. The result of $\mathrm{C} 2$ (avg. $=2.9$ ) is the lowest one. It shows that the subject does not understand the meaning of individual patterns, or misunderstands, resulting in a decline in score performance.

The image of the bamboo forest is not apparent. Some people think that it is a crossing path. The picture of the black-faced spoonbill of wetland crabs tends to be on the coast, and the wetland remediation in the earth-rock flow area belongs to the stream pattern. Apes and fireflies can be used as signs. Students are less familiar with ecological engineering methods, such as how the pond relates to environmental engineering methods. The villa construction image must be able to show the damage to the land caused by the development. Winding rivers dominate the image of forest rejuvenation, and the display of forest elements needs an increase.

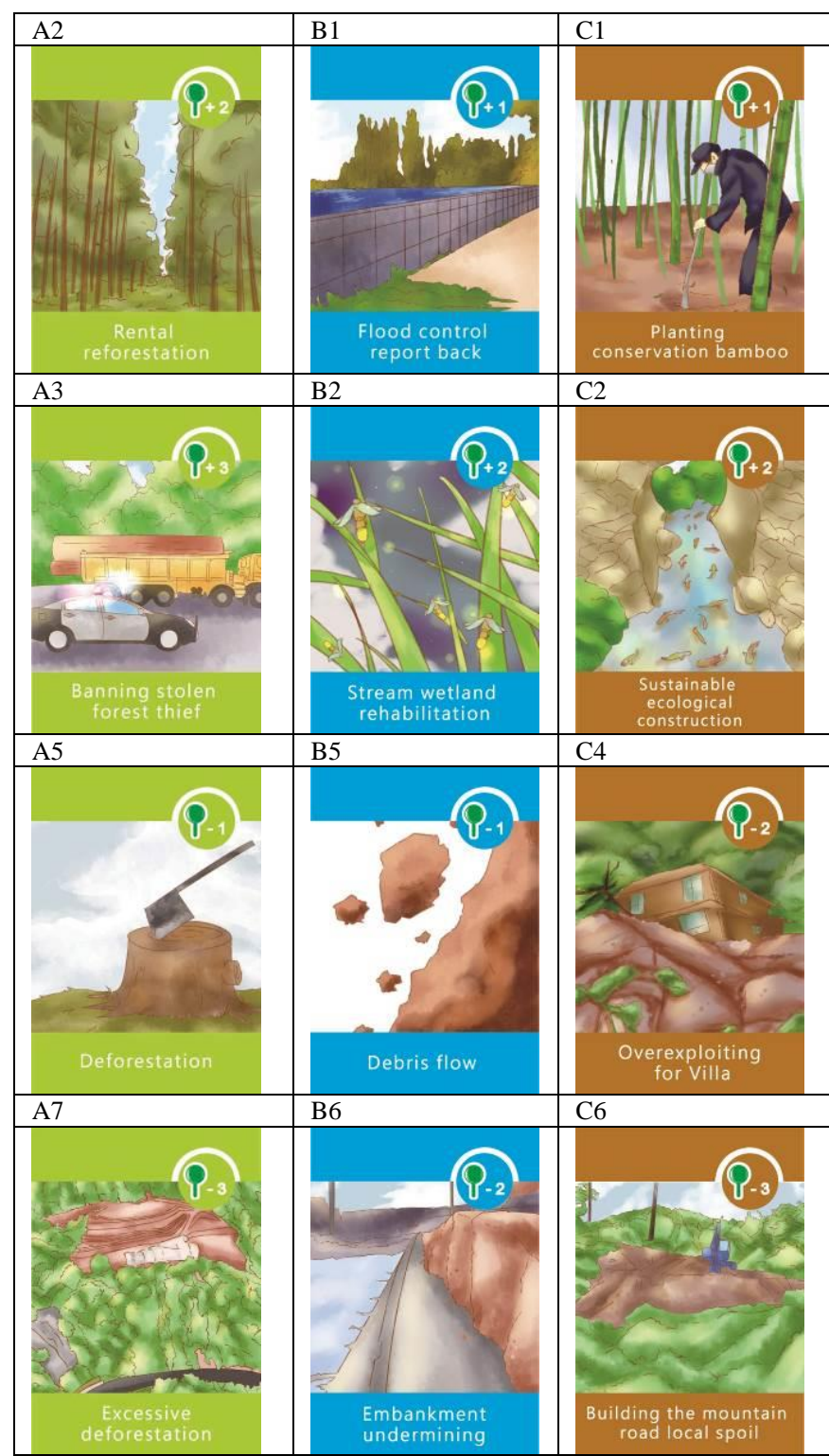

Fig. 4. A sample of a modified design of graphic representation use in an expert interview. 


\section{B. Expert Interview}

Fig. 4 display some examples of modified visual representation which use an expert meeting. After the extensive user interview, we have made some design corrections for some of the patterns. For example, in the afforestation of the a 2 map of Fig. 4, we emphasize the image of forest growth. In the A3 stealing wood theft, we insisted on the image to the police's suppression. In the pattern of the wetland re-cultivation of $\mathrm{B} 2$, we changed the design of wetland creatures that used to use the coast and replaced them into reforestation of mountain forest fireflies to clean the water resources. In the bamboo planting of $\mathrm{C} 1$, the image of farming emphasized. In the $\mathrm{C} 2$ ecological method, the characteristics of reducing the use of cement in the ecological engineering method and using more natural materials emphasized. In the $\mathrm{C} 4$ development of luxury mansions in the mountains, we underscore the danger that the villa may cause the hillside to collapse.

Experts give professional advice concerning mainly on the scientific knowledge of landside and natural conservation. They expect the graphic patterns transfer the meaning of the content in the specialized discipline. The three experts invited and related backgrounds are as follows. Expert 1 is a master's degree in geophysics that has 12 years of experience in engineering. Expert 2 graduated with a master's degree in land and water conservation and had six years of civil engineering experience. Now, he works in an engineering consulting company. Expert 3 graduated from Environmental Engineering and currently serve in the Environmental Protection Agency. Experts are invited to look at the eco-event cards with a graphic representation, and the text content. Then, we request expertise to write down comment on the extent to which it fits. The grade of the score is 1 to 6 points to increase the resolution. The average rating (refer to Table II) of the three experts is the basis for this evaluation.

TABLE II: THE AVERAGE SCORE OF THE THREE EXPERTS

\begin{tabular}{cccccccc}
$N=$ & 1 & 2 & 3 & 4 & 5 & 6 & 7 \\
\hline$A_{\text {avg }}$ & 5.7 & 5.0 & 3.7 & 4.3 & 3.3 & 4.0 & 3.3 \\
\hline$B_{\text {avg }}$ & 3.0 & 5.3 & 5.0 & 4.3 & 2.7 & 3.7 & 5.7 \\
\hline$C_{\text {avg }}$ & 4.3 & 4.0 & 4.3 & 5.7 & 5.3 & 5.0 & 4.7 \\
\hline
\end{tabular}

The results of the expert evaluation totaled an average of 4.4 points, indicating that the design of the 21 patterns is generally close to the scientific content. Of the 21 figures, six were below 3.7, with B1 and B5 being the lowest. We can explore where the images need improvement from the results themselves or the expert's arguments. Individual arguments are the list in below. In the opinions of expert interviews, we can find that they often pay more attention to the relationship between cause and result (causal relationship), because the connection between different reasons and outcomes is an essential step of concept guidance. Part of the pattern is only a single expression of concepts. Experts hope to interpret from a more general, holistic perspective.

A3 - Prosecuting "mountain rats."

This picture is excellent in that it illustrates policies actively hunting down and punishing mountain rats from illegally cutting down protected tree species, protecting the forests of Taiwan. The purpose of banned mountain mice is to preserve precious wood, non-soil conservation

A5 - Cutting down forests.

Pros: Shows the damage from cutting wood with the ax sticking into the tree

Cons: Only one tree is shown. More trees reveal that this is a more massive scale problem.

A7 - Over trim of forest

It can be changed to the purpose of arbitrarily developing hillsides and replacing the use of forest land. The color of land is green still, it un-consistent with the results of over-trim.

B1 - Flood Alert

Cons: add a sign or an app that execute flood alert. The meaning of "checking" is unknown. It may change to a flood warning. The wall texture represents overflow of a swimming pool.

B2 - Restoration of streams and wetlands

This picture is good. The streams and wetland restoration shows increasing in the population of fireflies. This is a pleasing sight to see for tourists.

B3 - Rainwater and land conservation

It's hard to understand the primary way of rainwater conservation.

B4 - Flooding in the river valley

Pros: Shows the imminent threat to the house.

Cons: Can show the house being half submerged in water B5 - Mudslides and rockslides

Cons: I would suggest something like a mudslide covering a road. The surface looks like a collapse, not a rock flow.

B6 - Erosion of riverside levees

Cons: It's hard to understand at first glance that the levee is being eroded. The erosion can be display through section view and water movement.

B7 - Sedimentation at dams: This one is good and pretty straightforward

C1 - Planting bamboo forest

The bamboo forest will be controversial. It is recommended to change to a conservation forest,

C2 - Sustainable ecological engineering methods

It seems that the environmental engineering method used here is that a tunnel is created for fish to swim through. A broader view of environmental engineering methods could be used. Reducing the use of concrete promotes water permeability and biodiversity.

C3 - Enforcing soil water conservation policies

Perhaps add a picture about environmental police examining environmental conditions

C4 - Inappropriate villa development

This one is good. It communicates that although houses built on hillsides may look aesthetically appealing, it is also dangerous if it is created right by an unstable slope and doesn't have deep foundations, and destroy during stronger typhoons

To improve recognition speed of an object, a designer can use a simple drawing of the object. This approach makes it easier to recognize, and thus make the object easier and faster to identify. 3D representations on the screen may slow down 
recognition and comprehension [9]. The visual cortex is active when people imagine something [10]. If the information is not in categories, people feel inappropriate and try to re-organize the information on their own.

\section{CONCLUSION}

We use three elements of interaction (land, water, and forest) to present their relationship. Simplify the terminology of cards reduces the complexity to lower the barrier of using in environmental education. The graphic representation made participant aware it's meaning and how things are happening in our surroundings. The game activities and knowledge build a mutual connection. From the survey an expert interview, we extend the confidence of graphic representation. A gap between artistic depiction and scientific expertise is noticed. Designers must have scientific knowledge and create according to with the guidance of experts to be able to present scientific concepts in the form of images.

\section{REFERENCES}

[1] C.-H. Wu, S.-C. Chen, and Z.-Y. Feng, "Formation, failure, and consequences of the Xiaolin landslide dam, triggered by extreme rainfall from Typhoon Morakot," Taiwan. Landslides, vol. 3, pp. 357$367,2013$.

[2] S.-C. Chen and C.-Y. Wu, "Debris flow disaster prevention and mitigation of non-structural strategies in Taiwan," Journal of Mountain Science, vol. 11, no. 2, pp. 308-322, 2014.

[3] H. L. Wu and Z. Feng, "Ecological Engineering Methods in Soil and Water Conservation of Taiwan," Ecological Engineering, vol. 28, no. 4, pp. 333-344, 2004.

[4] S.-J. Hsu, "The effects of an environmental education program on responsible environmental behavior and associated environmental literacy variables in Taiwanese college students," The Journal of Environmental Education, vol. 35, no. 2, pp. 37-48, 2004.

[5] F. Gobet et al., "Moves in mind: The psychology of board games," Psychology Press, 2004.

[6] J. P. Zagal et al., "Collaborative games: Lessons learned from board games," Simulation \& Gaming, vol. 37, no. 1, pp. 24-40, 2006.
[7] Z. Tóth, "Mapping students' knowledge structure in understanding density, mass percent, molar mass, molar volume and their application in calculations by the use of the knowledge space theory," Chemistry Education: Research and Practice, vol. 8, pp. 376-389, 2007.

[8] F. L. Chao et al., "Information organization of 3-D landslides board game for ecological educations," IOP Conference Series: Earth and Environmental Science, 2018 Jun, vol. 159, no. 1, pp. 012018.

[9] S. Weinschenk, 100 Things Every Designer Needs to Know about People, 2011, p. 21, ISBN-13: 978-0321767530.

[10] S. Robert et al., Cognitive Psychology, 7th ed. Boston: Allyn and Bacon, 2005.

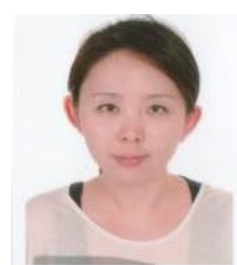

Syuan-Lan Shih was born in Taipei, Taiwan, ROC, in 1981. She received the B.S. degree from National Taiwan University of Art, in 2004, and M.S. degree in industrial design from Konstfack University in Sweden, in 2011. She is studying the Ph.D.of architecture and urban design in Chaoyang University of technology now.

She is an assistant professor in the Industrial Design Department at the Chaoyang University of Technology. Her research interests include the product design, eco-design, and education in product development.

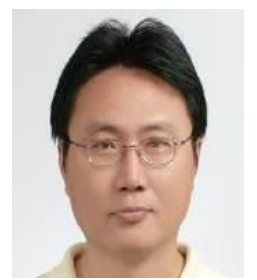

Fang-Lin Chao was born in Taipei, Taiwan, ROC, in 1958. He received the Ph.D. degree in electrical engineering from National Taiwan University, in 1991.

He joined the Electronic Research and Service Organization, Industrial Technology Research Institute, Hsinchu, Taiwan, in 1982. In 1994, he was an associate professor with the Department of Industrial Design at Da-Yeh Institute of Technology. Since September 2004, he has been an Associate Professor with the Department of Industrial Design at Chaoyang University of Technology, Taichung, Taiwan. His research interests include eco-design and design integration in product development.

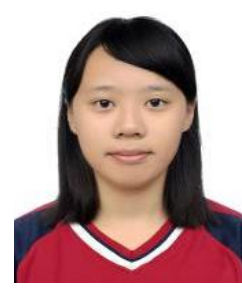

Wen-Ting Tao was born in Taoyuan, Taiwan, ROC, in 1998. She is studying B.S. of Industrial design in Chaoyang University of technology. Her research interests include the product design and education in product development. 